\title{
COLLECTED PAPERS OF THE ROWETT RESEARCH INSTITUTE
}

\begin{abstract}
$7 \mathrm{HE}$ work done at a large research centre such as the Rowett Institute is necessarily published in a wide variety of journals. It is therefore very helpful when, at regular intervals, a collection of its recent publications becomes available. Volume 14 of the Rowett Institute papers has just been issued*. It contains reprints of more than 60 papers and cites another 30 by title only. Practically all the 94 publications appeared in 1956 and 1957. Several of them will be of interest mainly to the practical man since they deal with subjects of such considerable practical importance as winter grazing in north-east Scotland, methods of extending the grazing season, the rearing of calves and the management of the breeding ewe. A large proportion of the papers, however, are devoted to the valuable basic research work done by the Institute on subjects such as the biochemistry, physiology and microbiology of the rumen, water metabolism in the sheep and energy expenditure in livestock. Some of the other fundamental work described in the collected papers is concerned with the metabolism of short-chain fatty acids

* Rowett Research Institute. Collected Papers, Vol. 14. (94 papers.) Summary and Subject Reviews. Pp. ii 54. (Bucksburn, Aberdeenshire: Rowett Research Institute, 1958.)
\end{abstract}

and with enzyme studies, particularly work on the glucuronidases.

An important feature of the volume is the fact that it contains a summary extending to 54 pages which is also issued separately from the bound volume and which can be obtained by applying to the Rowett Research Institute. This separate summary begins by giving an account of the history and aims of the Institute, and contains not only a list of all the papers that are collected together in the bound volume with their titles and references, but also a concise account of the work they describe written by the director, Dr. D. P. Cuthbertson. The summary contains also two review articles which are in fact progress reports on two sections of the Institute's work. One deals with glycosidases and their inhibition by aldonolactones and has been written by Dr. G. A. Levvy. The other is a description by Dr. J. Duckworth of the work his Department has been doing on the skeleton in lactation and growth. Both the bound volume and the separate summary can be highly recommended to all who are interested in the recent advances that are now being made, not only in many practical aspects of animal nutrition, but also in the fundamental principles on which the subject is based.

\section{RIBONUCLEOPROTEIN PARTICLES FROM ESCHERICHIA COLI}

\author{
By Dr. A. TISSIÈRES and DR. J. D. WATSON \\ Biological Laboratories, Harvard University, Cambridge, Massachusetts
}

\begin{abstract}
$\mathrm{T}$ HE amount of ribonucleic acid in exponentially growing Escherichia coli cells with a generation time of about $30 \mathrm{~min}$. is of the order of 25 per cent of the dry weight of the organism. This value varies inversely with the time of generation and seems directly related to the synthetic ability of the cell ${ }^{1-3}$. About 90 per cent of this ribonucleic acid is bound to the ribonucleoprotein particles, which thus form a major constituent of the bacterial cytoplasm. These particles were first described on electron micrographs of $E$. coli lysed by phage $\theta^{4}$, and later it was discovered that they contain the bulk of the ribonucleic acid of the cells ${ }^{5}$. They have been found in extracts of all bacterial species so far examined ${ }^{5,6}$. They resemble closely by their size, chemical composition, and several other properties the ribonucleoprotein particles which have been studied in detail in animal and plant tissues ${ }^{7-10}$ and in yeast ${ }^{11}$, and which are generally believed to be the site of protein synthesis ${ }^{12,13}$.

In some animal tissues, such as the pancreas, most of the ribonucleoprotein particles are attached to the reticulum and they can only be isolated after dissolving the membranous material with deoxycholate ${ }^{8}$. In other tissues, however, most of the particles appear to be free in the cytoplasm ${ }^{14}$. The significance of this difference is not known. In bacterial extracts the particles are free. This suggests that they are either free in the cytoplasm or else attached to a very loose structure which collapses when the cells break open.
\end{abstract}

The early experiments of Schachman, Pardee and Stanier ${ }^{5}$ with bacterial extracts indicated the presence of two main fractions with sedimentation constants of $29 S$ and $40 S$, which suggested that the bacterial particles might be smaller than those from other sources. Recently, however, several investigators (ref. 15 and personal communication from Spiegelman, S.) have observed the presence of larger particle fractions, characterized by $60 S$ and $80 S$ when the bacterial extract contained a high concentration of magnesium.

The experiments to be reported here confirm the stabilizing role of magnesium, and indicate that under suitable conditions four types of ribonucleoprotein particles may be observed $(32 \mathrm{~S}, 51 \mathrm{~S}, 70 \mathrm{~S}$ and $100 S)$. The $70 S$ particle will be shown to break down into the $32 S$ and the $51 S$ components. Both these smaller units can be obtained in stable conditions, and their properties, as well as those of the $70 S$ and $100 S$ particles, will be reported and discussed. The sedimentation constants given here were corrected to $20^{\circ} \mathrm{C}$. and zero concentration. They are $10-20$ per cent higher than those of other workers. This may possibly be explained by the fact that they were measured on isolated particle preparations.

Preparation of Extracts and of Ribonucleoprotein Particles

$E$. coli strain $B$ was grown in broth, at $37^{\circ} \mathrm{C}$, under forced aeration. The cells were harvested in 